\title{
Feedback as a Relational Concept in the Classroom.
}

To be published in The Curriculum Journal

Accepted on $30^{\text {th }}$ May 2019

Ruth Dann

University College London, Institute of Education

\section{Abstract}

This paper constructs a theoretical argument to frame feedback as a relational concept. It addresses contemporary concern that formative assessment, of which feedback is a part, is under theorised. The arguments presented link to existing theoretical and research evidence. The paper also challenges the dominant policy discourse in high stakes assessment contexts in which feedback is typically seen in technicised ways to serve the need to raise measured pupil outcomes.

Vygotsky's notion of the Zone of Proximal Development is explored as a relational space in which both teachers and learners understand differences between learning 'now' and learning 'next'. Extending Vygotsky's perspective, a socio-cultural perspective is offered, by considering the role of 'others', 'language', 'activity' and 'identity', as part of the process of sharing and understanding feedback in classrooms. The work of Holland et al (1998), Bakhtin (1986) are central to the developing argument. The paper reveals feedback as a complex situated process, requiring mediated dynamic interaction, where feedback is appropriated as a cultural artefact by its participants. The implications of such an articulation demands a greater sense of understanding pupils' roles in feedback and the importance of teachers enabling pupils to see themselves in new ways as future learners. 
The purpose of this paper is to explore the notion of feedback as a relational concept. In so doing feedback is identified as far more complex than might hitherto be recognised. The technicised formulation of the curriculum, particularly that which is measured, has come to dominate our education system in England, and has been translated into pedagogies of practice, which seek particular visible outcomes (Dann, 2018). Success is pre-determined by expected statistical outcomes. Feedback has often been highjacked as a technique which supposedly serves the transmission of the curriculum to the learner and highlights where adjustments might be made (to teaching or learning) so that the best visible outcomes, can be yielded (Torrance 2012). Despite three decades of reform which has cemented the National Curriculum in England, and its associated testing into the fabric of our education system, there are still clear messages that pupil attainment is not sufficiently high, the school system fails particular types of children, and it laggs behind other higher performing countries (DfE, 2010 and 2016).

The literature on classroom feedback has been dominated by research that seeks to identify 'what works' to gain the greatest measured outcomes for pupils. Although there is some need for such research which can point to priorities and starting places for implementation, as Black (2015) and Baird et al (2017) point out, much of the research has not been sufficiently theorised. Feedback is typically seen as a key component of formative assessment, even when used to drive forward learning which will ultimately be part of summative assessment. Although it is seen mainly in the context of conceptually framing the concept of formative assessment (Black et al 1998, Wiliam, 2011, 2016), feedback requires a more coherent theoretical exposition. This paper seeks to present theoretical underpinnings for the complex interactional process of feedback which is situated in classrooms, but which requires mediated dynamic interaction. It also sits alongside more recent theorisation of the broader notion of formative assessment (Black and Wiliam 2009 and 2018). The pathway which is explored is problematic and perhaps even perilous if it is to be used for simple solutions in classroom contexts. It does not offer simple technical solutions. Although it does not negate the possibility that simple direct exchanges may be sufficient for both teachers and pupils to easily position themselves for the progression of learning. The paper highlights that seeing feedback mainly as words (spoken or written) often presumed to come from the teacher to the learner, offers a limited and potentially distorted version of the likely way in which feedback is acted upon. The importance of the language shared must be understood in a broader context of the way in which pupils understand themselves as learners and how their own learning dispositions are shaped through their identities as learners within school communities. Some learners may easily make sense of themselves as learners and have the tools to 'self-author' (Holland et.al 1998) in ways which are in keeping with the priorities of the school. Other pupils may find this more difficult. Instead of tightening the language of feedback, increasing its frequency and narrowing the curriculum in an attempt to refocus their learning to what the school system requires, there needs to be a better understanding of that shared space in which pupils ' can be supported to understand their next steps in learning. Such learning cannot be regarded in terms of isolated components of an external curriculum, but of new knowledge that needs to be understood and related to a person. New learning will become part of the learners' own self-authoring and part of their developing life in a world that extends beyond the classroom. 
Developing an evidence-based argument to support such a position is the focus of this paper. It is structured through eight sections. Firstly, the context and focus of feedback is examined in relation to contemporary classroom settings. This is followed by consideration of the prevailing high-stakes policy context. The focus here is on England but does not preclude other jurisdictions in which there is a national curriculum and high stakes testing. Following this, some of the assumptions which are often taken for granted in using feedback in classrooms are teased out. Having laid the groundwork for understanding and contextualising feedback both within formative assessment and within a policy context, the emphasis then shifts to the forth section which considers how we might explore feedback differently. Relational understandings of feedback are examined through socio- cultural theory, and in particular through Vygotsky's notion of the zone of proximal development. Extending from this theoretical position, feedback is then explored through four key strands which position it as a relational concept using socio-cultural theory. These four strands focus on the role of others, language, activity and identity.

\section{Context and Focus of Feedback}

Interest in and research about feedback has been sustained over several decades. Significant claims have been made for its effects on pupils' learning which have kept it at the forefront of formative assessment theory, policy and practice (Black and Wiliam, 1998, Hattie and Timperley, 2007; Hattie, 2009; Wiliam, 2011). One of the most widely used definitions of feedback was from Ramaprasad (1983:4) which was subsequently developed by Sadler (1989:121) as 'information about the gap between the actual level and the reference level of a system or parameter which is used to alter the gap in some way.' In a broad sense there is agreement that feedback is useful, perhaps even essential to ensure that learning, within a formal school system progresses. However, in the research literature there is an overwhelming sense of tension, conflict and complexity related to what sense is to be made of feedback so that it might support both teaching and learning. Indeed Latham and Locke (1991: 224) suggest "few concepts have been written about more uncritically and more incorrectly than that of feedback". Furthermore, much of the research evidence points to instrumental uses of feedback, and its implementation is mainly associated with 'what works' in a data driven accountability educational system (Dann, 2018).

Meta-analysis of the impact of feedback on learning has shown positive results. In England the Educational Endowment Foundation with the Sutton Trust host the Teachers' Toolkit (2014). This offers an evidence-based resource which presents research behind a range of practices and interventions for use in schools. It offers a very high effect size for feedback equating to +8 months gains in pupil outcomes. Such evidence sits alongside a range of meta-analysis studies which identify the effect size of feedback to range from 0.4 - 0.7 (Hattie and Timperley 2007; Kluger and DeNisi 1998, Kingston and Nash 2011, 2015). Shute (2008) in her study found evidence for the effect size of feedback to range from $0.4-0.8$. Evidence certainly points to feedback as a mechanism that can promote learning. However, as Kluger and DeNisi also highlight, one third of their studies showed feedback to have a negative or damaging effect. As Wiliam (2016) so emphatically points out, the claims made through such meta-analysis are often 'seriously misleading' (84). When a broader range of studies on feedback are examined, and issues are considered in greater depth, feedback requires a level of understanding and application that currently seems to be under represented in research in school contexts. The research evidence related to higher education offers more exploratory insights 
to feedback and begins to expose more of a relational exposition. Although this seems to be mainly through the notion of dialogic feedback (Carless, 2013; Steen-Utheim and Wittek, 2017). This paper seeks to seize the concept of feedback and, to consider it as an essential and pivotal concept within formative assessment in schools. It particularly extends Black and Wiliam's (2018) contribution to focusing on formative assessment in the context of instruction with an emphasis on interactional dialogue and pupil interpretation. Furthermore, it links to Black and Wiliam's (2009) priority to look more closely at models of learning as part of how formative assessment is actioned and interpreted. It offers a theoretical positioning which may enable a more robust and actionable set of understandings, supporting more productive ways of further developing feedback. It draws together cognitive, relational and communicative aspects of feedback.

\section{Feedback within the theory of formative assessment}

Conceptually in this paper, feedback is considered within the parameters of formative assessment. The term formative assessment is used in its more recent framing which shifts it from its earlier versions which were located more in terms of evaluating and adapting teaching (Scriven, 1967) to enabling changes in both teaching and learning to promote achievement. Understanding formative assessment subsequently, takes account of the work of the Assessment Reform Group, formed in the late 1990s, who identified that formative assessment had perhaps become a problematic concept and introduced the term 'Assessment for Learning'. This framing offered a stronger emphasis on the pupil role in the process. Their widely used definition stated "Assessment for Learning was the process of seeking and interpreting evidence for use by learners and their teachers to decide where the learners are in their learning, where they need to go, and how best to get there" (Broadfoot et al 2002: 2-3). Further to this definition, key strategies were distilled. Wiliam (2012:2) distils these as developing: learning intentions and success criteria that are clarified and shared; classroom activities which can yield evidence about learning; feedback designed to move learning forwards; learners becoming resources for each other; learners as active owners of their own learning.

The terminology of Assessment for Learning and formative assessment seem embedded in their chronology of development. However, there is still lack of clarity over whether one replaces the other, are they the same thing and can they therefore be used interchangeably or do they mean slightly different things? Black et al (2004:10) offered some additional clarification of the distinction between AfL and formative assessment. They suggested that AfL relates to assessments which are specially designed to promote pupil learning whereas formative assessment would refer to whether they were actually used to improve learning. (They highlight a similar distinction between Assessment of Learning and summative assessment, separating design and function). Although this does offer a helpful distinction in some ways, this subtly is often lost in contemporary literature and perhaps echoes Bennett's (2011) suggestion that the reality and the purpose are not sufficiently distinguishable. Wiliam's more recent work (2011 and 2016) highlights formative assessment as a priority, which seems to give particular emphasis to what is actually enacted. He defines formative assessment in the following way

An assessment functions formatively to the extent that evidence about student achievement is elicited, interpreted, and used by teachers, learners, or peers to make decisions about next 
steps in instruction that are likely to be better, or better founded, than the decisions they would have made in the absence of that evidence (Wiliam, 2011: 43).

Locating feedback within formative assessment is thus a key step in this paper. It is not so much the design of a feedback tool or technique which is pivotal but whether or not it enacts some form of change through the interactions of participants that is being explored. This is an important emphasis for the way feedback is contextualised as part of formative assessment. More recent attempts to theorise formative assessment have tried to establish it more strongly within notions of pedagogy, or more specifically as an aspect of instruction (Black and Wiliam, 2018) Also, in their 2009 paper Black and Wiliam have given consideration to the importance of theorising formative assessment in relation to theories of learning. They highlight the importance of understanding feedback in relation to the 'inner mental life' of pupils (2009:13). This paper examines feedback in a way that locates it between instruction and learning and opens up the relational space around pupils and teachers, between the persons as well as the actions, for additional theoretical positioning which would enhance and extend the current literature.

\section{Policy context in England for understanding feedback}

Gaining a greater grasp of the policy context surrounding the use of classroom assessment and feedback is important for establishing a context for unravelling the way in which feedback is often currently shaped and why there might be a compelling need to consider it differently. In England, policy priorities have translated into particular classroom practices. Assessment lies at the heart of such controversy in terms of its influence on classroom practice and priorities. The prevalence of high-stakes testing has been a global educational phenomenon. Such tests were clearly identified by Madaus (1988: 29) as having very clear consequences (rewards or sanctions) for schools, teachers and or learners. This results in particular types of behaviours which are aimed at maximising test scores (Popham, 1987). Such an impact is not confined to England and can be evidenced in Australia (Lingard, (2010) and the USA (Au, 2011; Tanner, 2013) and wherever high-stakes testing prevails. In England, education policy seems to have been more tightly encircled by the results of high stakes assessment since the National Curriculum was first introduced in 1988. The likely responses to highstakes tests, such as teaching to the test, so clearly outlined by Madaus, feature strongly in schools (Stobart and Eggen, 2012) as do a range of other intended and unintended social consequences (Hanson, 1994). Alderson and Wall (1993) used the term 'washback' to illustrate how high-stakes tests influence and shape other educational practices related to them. It is clear from research such as from Au (2011) and Tanner, (2013) in the USA that teaching practices and curriculum content are constrained and shaped by test content.

In addition, there is clear evidence from the UK government's own commission (DfE, 2015) to reveal that national tests overshadowed and distorted other assessment practices. The Commission on Assessment without Levels, whose report preceded the government in England removing the National Curriculum levels, highlighted that the rationale for this action was a response to the way in which the levels (assessment categories used to show attainment) had come to dominate classroom practice, overshadowing the focus of teaching and learning (DfE, 2015). The summative assessment system had dominated and distorted formative assessment within classes. Furthermore, the relationship between teachers and pupils was increasingly defined in the context of teachers needing to ensure that pupils yielded the required test data to characterise themselves and their schools as performing well (Pratt, 2016). Feedback within formative assessment was increasingly 
driven by summative outcomes which were determined by externally determined outcomes (Dann, 2018).

The dominance of an education system which is regulated by performance outputs has been increasingly evident in recent decades. Ball (1993: 106) identifies that 'the curriculum provides for standardisation and testing for normalisation - the establishment of measurements, hierarchy and regulation around the idea of a distributary statistical norm within a given population.' The intensification of the way in which the curriculum has been translated into particular forms of data, through testing, signifying the performance of schools, teachers and pupils, has characterised education in England as well as in other jurisdictions. International performance data such as through the Programme for International Student Assessment (PISA), Trends in International Mathematics and Science (TiMMS), and Progress in International Reading and literacy (PIRLS) has broadened the reach and further legitimised such approaches as outcomes become not only national commodities but global ones where countries, institutions, practitioners and students must strive to yield (or be) the data which denotes both progress and success. The educational world of 'datafication' so clearly encapsulated by Bradbury and Robert-Holmes (2018) in the primary and early years, seems to pervade the way in which education is framed and measured. As a consequence participants in the 'production' of education are shaped in particular ways which have a profound effect on what they do and how they behave.

In essence what this system has yielded is a profession which works exceptionally hard to produce the best 'data' possible. The data is focused on subject knowledge, in particular areas of the curriculum. Classroom practice becomes dominated by the tested curriculum and data which reveals pupil progress and attainment. Formative assessment thus becomes a mechanism to deliver the prioritised outcomes which are predetermined and imposed beyond the classroom. Feedback becomes a technicised process as it is seen as an important instrument of convergence (Torrance and Pryor 1998) and focuses pupil learning in these predetermined ways (Dann, 2018). Teachers, in this performance driven educational system assume the role of 'primary knower' and 'monitor or judge' of value (Nassaji and Wells, 2000). This is translated into many of their practices in giving feedback.

Currently, the dominant discourse on results and outcomes does not seek to be concerned with learning as a process, just a product. Assessment for learning has been considered with this very divide being challenged by Bennett (2011) who considers that it cannot be considered merely in terms of whether it is a process or an instrument. It seems Baird et al (2017) are offering the same challenge to both formative and summative assessment. To some extent there is an imperative to seek greater clarity in the relationship between assessment and learning. Exposing theoretical perspectives which underpin both assessment and learning thus becomes important. As feedback serves both formative and summative assessment and it is at the interface of assessment evidence which is designed to change future learning and or teaching, it has the potential to make a contribution to helping to establish greater clarity in the links between the two. However, there is no neutrality here. There must be a justification and positioning which will incorporate values and beliefs. Since such a narrative is marginalised in an educational arena in which so much of what is prioritised is camouflaged as objective evidence, there seems to be a difficulty in exposing other 
ways of making sense of the complex interplay between assessment and learning. Nevertheless this paper seeks to address these complex issues and to peel back the dominant discourse which seeks uniformity, standardisation and an objective reality. Exposing some of the assumptions which are frequently not articulated are usefully brought to the fore before looking more closely at how feedback is framed as a relational concept.

\section{Assumptions and Priorities}

Assessment literature on formative assessment is punctuated with cautions (Bennett 2011), suggestions of distortions (Torrance, 2012), and declarations of over inflated claims (Wiliam 2016). There are particular assumptions that lie at the heart of definitions of formative assessment and feedback which are often unchallenged. Black et al (2006) highlight the assumptions that pupils are 'intentional learners' and have the pre-dispositions and mind-set to take on the central role in formative assessment. Shute (2008:157) highlights different cognitive reasons why pupils may respond to feedback in different ways, including lowering its cognitive challenge or ignoring it. Pryor and Crossouard (2008:14) from a socio-cultural theory perspective, recognise that formative assessment demands a lot from students. They may well resist more demanding and different practices partly due to their previous experiences with assessment. Thus, in establishing what formative assessment and feedback might be and who and what participants might do is not straight forward and must include addressing a range of assumptions both practically as well as theoretically.

In exploring some of the theoretical premises and assumptions underpinning formative assessment (and feedback) there is concern that these may not be sufficiently articulated. Torrance, (1993) outlines how theoretical assumptions for formative assessment might be regarded as either behaviourist or constructivist and the ways in which assessment is subsequently enacted becomes increasingly problematic. He claims that the potential of constructivist perspectives is less likely to be realised without far more clear delineation (337). Black, (2015) indicates that the some of the claims made for formative assessment went beyond the existing research evidence and was not well clarified in terms of pedagogical or learning theory. Although there is some progress here (Black and Wiliam 2009, 2018, Baird et al 2017), there is still a lack of in-depth scrutiny, application and consideration of theoretical principles that frame notions of the ways in which formative assessment is conceptualised or enacted which perhaps have created particular tensions as time has progressed. Black makes reference to a particular tension when carrying out the research undertaken with teachers in Oxfordshire. When teachers were asked to leave aside summative assessment, whilst they were engaged in the formative assessment project, they indicated that this would not be possible. Teachers needed to be able to work with both formative and summative assessments. However, if some of the principles and theoretical positionings are different, or even in tension, how easy would this be? The importance of trying to theorise both formative and summative assessment so there is better synergy between them has been a more recent priority (Black and Wiliam 2018, Harlen (2005). It is perhaps the lack of dissemination of principled theorisation, together with a policy context which seems to have fractured attempts to link formative and summative assessment that has contributed to shaping the way formative assessment has been enacted in recent years. This effects all participants - pupils and teachers. 
As the discussion so far has argued, feedback in schools is largely seen as a process which draws on assessment evidence and is used to alter a gap between learning now (actual) and learning next (reference). Research already highlighted points to differing approaches to making sense of and using feedback. Typically, prevailing policy contexts, which determine outcome priorities have shaped feedback in particular ways. Increasingly there is a recognised disconnect between teaching, learning and knowledge - with a culture of establishing feedback as a technical tool to bring about specific prevailing outcomes. There is certainly good reason why feedback might be tightened to more accurately reflect teaching objectives. There is a validity argument here which might claim that the feedback should be as closely related to the intended learning outcomes as possible for it to be considered valid for its purpose of helping to maximise pupil outcomes. If validity is considered only in terms of content or even constructs, then this view of validity might make sense. However, as Newton argues (2007 and 2012) validity cannot be constrained to content and construct issues. Conceptualising validity arguably requires considered of both interpretation and use of information. Hence social consequences become as important as content in the contested grounds of validity theory. In the context of feedback, attention should be given to both the content of the feedback as well as how this is interpreted and used. Therefore, even in the realms of looking to establish how validity claims can be made for feedback, there is an imperative to look to the relationships between the information conveyed and the way it is used. This further opens up a space for feedback to be seen relationally rather than merely technically.

But what if the gap which feedback is designed to alter is explored differently, not as the gap in which knowledge and content is taught, learned and measured, but as an interactional space in which teaching and learning are co-constructed? How might such a conceptualisation alter or influence the way in which we make sense of feedback. Pryor and Crossouard (2008) began to assemble a version of formative assessment which revealed how socio-cultural perspectives might be embedded and interpreted. This built on Torrance and Pryor's (1998) work, and offered a stronger theoretical basis which extended from constructivist perspectives to socio-cultural theory. Of particular priority was to explore what was often taken for granted in formative assessment, mainly that it is complex and that participants may see and interpret events differently because of their different cultural and historical contexts both within and beyond school. Furthermore, Pryor and Crossouard's (2008: 8) work recognised the social nature of formative assessment, particularly through the use of language. This paper explores how the notion of feedback fits into formative assessment with a clearly articulated theoretical basis and can be seen as a relational concept which links to socio-cultural theory. It centres on four concepts which can be drawn from socio-cultural thinking but require careful consideration in the context of exploring feedback. These four key concepts are: the role of 'others', language, activity and identity. However, before these are explored in more detail the notion of the learning gap requires more extensive exploration. The first step in making sense of feedback relationally is to understand this 'gap' differently. As a step towards this endeavour Vygotsky's notion of the Zone of Proximal Development (ZPD) is used to explore and challenge the notion of the learning gap. This draws on existing socio-cultural development theory, which is focused on a space framed to shape next steps of learning. On the surface this seems to offer a useful way of shaping the space in which feedback might be better 
understood and in which participants communicate and engage in joint activity which shapes future teaching and learning.

The zone of proximal development as a concept for exploring feedback.

Vygotsky's initial definition of the ZPD has clear relevance to the way in which notions of a gap are framed in a teaching and learning context. It therefore has potential to be linked to making sense of both the content and form of feedback from a socio-cultural perspective.

"It is the distance between the actual level developmental level as determined by independent problem solving and the level of potential development as determined by independent problem solving under adult guidance or in collaboration with more capable peers" (Vygotsky, 1978:86).

The ZPD explores the way in which teaching and learning occur ahead of development and is the space in which the potential for learning is best understood. Vygotsky claims it is more important to understand than actual achievement which is determined retrospectively (Vygotsky 1978:86). Thus the prospective nature of the ZPD is critical. This exemplifies the way in which Vygotsky positioned his work to counteract the rise of intelligence testing and his vehemently expressed concerns that children, who were supposedly achieving the same scores when their achievements were measured, responded quite differently in new learning contexts. This concern with future learning certainly has resonance with the notion of feedback. Seeking to understand the way Vygotsky tried to make sense of the ZPD offers rich potential for trying to understand and develop feedback as a relational concept.

The use of the notion of the ZPD also gives a different framing for how the assessment judgments made by teachers in formative assessment might be mediated through feedback. The quality of teachers' judgments in assessment have certainly been the subject of significant debate. This is particularly the case within discussions on the reliability of teacher assessment related to its use in summative assessments (Johnson, 2013). Here however, the focus is on formative assessment, rendering reliability potentially of less importance in that the assessment evidence is for the development of future learning and the possible adjustment of teaching in the classroom. Yet teachers have to make complex decisions as to how they attend to the learners' production of their work and the standards to which the work is referenced (Wyatt-Smith et al, 2010). There is also the likelihood that although formative assessment is in the moment of production, the teaching and learning are pointing towards explicit standards required for summative assessment. Understanding the gap between learning 'now' and learning 'next' requires teachers to be sensitive to individual pupil needs and the extent to which the reference level can be understood by pupils, taking into account their learning context and individual dispositions.

Thus the ZPD offers a way to steer towards better understanding the need for assessment judgments to be made, but also the need for feedback to mediate between the reference level and other contextual and social factors related to the possibilities of future learning. This shifts the emphasis away from only considering the dependability and reliability of teachers' judgments, to relating such judgments to models of learning. Furthermore, it links to Black and Wiliam's exposition on the importance of relating formative assessment to models of learning (2009) 
In drawing on Vygotsky's notion of the ZPD there must also be recognition that there can be difficulties trying to match one concept with another. Certainly Vygotsky's own work is complex to understand, and was not as developed as literature often suggests (Chaiklin, 2003, Gillen, 2000). It should not be used as a fashionable way to explain pupil differences (Mercer and Fisher, 1992) nor is it 'some clear cut space that exists independently of the process of joint activity' (Scrimsher and Tudge, 2003: 300). Rather it is the conceptual site for joint activity in which learning and teaching might advance.

Vygotsky certainly acknowledged that the ZPD would be framed by developmental phases or norms, which Chaiklin terms the 'objective' ZPD (2003:47). Here there is recognition that the boundary of the next steps or reference level must be in line with existing developmental steps. Thus the ZPD is aligned with 'buds of development, rather than the fruits of development' (Vygotsky 1978:86). Yet his conceptualisation was very much about allowing for uniqueness rather than uniformity in learning. This immediately shapes the learning gap in a very different light to the deterministic framework which is set out in prescribed curriculum policy and outcomes orientated attainment standards. However this does not make the two incompatible, but it does demand a different understanding of both. Given that there are developmental boundaries and some notions of norms and expectations, there is scope for particular curriculum and learning aspirations and directions to be incorporated. But any notion of curriculum content, which is the focus for learning and teaching should not be isolated from the context of the participants. This is fundamental to socio-cultural theory. In particular in this paper, it is fundamental to understanding feedback. As the array of research on feedback paints a confusing and sometimes contradictory picture, it is perhaps the very different research messages that are revealed, and the lack of consistency of what works, that raise questions about the behaviouristic approaches that so often shape practice. As I have argued elsewhere (Dann, 2018 and 2015) assumptions underpinning feedback that assume pupils are intentional learners, and wish to 'play the game' which schooling projects onto them are inadequate, and explain some of the differences in the effectiveness of varying feedback strategies. Such differences reveal how pupils' past, present and future impact on their experience of the situated context of school learning in highly complex ways. The research evidence itself therefore points to a need to understand the learning gap differently. It is not so much about a knowledge gap but a relational space in which knowledge, culture, language and experience all interact and intersect both between and within individuals. If feedback is to have any role in this space it must surely recognise and be interwoven into such relationships. Trying to make greater sense of how this might be possible and the ways in which decisions and insights about the use and interpretation of feedback can be understood is now explored in the following four sections which tease out four key conceptual strands.

\section{Feedback 'with' others.}

Definitions of feedback include the way on which it is usually provided by others so that adjustments can be made to future learning (or teaching). Focus is mainly on what is conveyed (i.e. the information) rather than who conveys it. Boud and Molloy (2013:699) use the phrase 'dangle the data' to describe how feedback is often seen in terms of the content conveyed. In practice the 'dangling' (how and who presents the information) often seems superfluous to the 'data'. As Boud and Molloy advocate, feedback needs to aim to become sustainable. Although they write with a HE context in mind they aspire for learners to be able to generate their own feedback and to self- 
regulate their learning through their own self- assessment. The shift of role here is something which needs to be part of a longer trajectory of change throughout a learner's education. The way in which feedback is shared between teacher and pupil throughout schooling can therefore not be a static process. In addition to a gradual shift of the dominant role from the teacher to the learner there is also an implicit notion here that there is some kind of dynamic relationship.

There is a juxtaposition of power, which needs to be reconciled. Feedback is typically conveyed as something which is given to another, for a purpose which will bring about change. Power to shape, time, control and focus it are mainly located with teachers within classrooms. Yet any notion of recognising it as successful requires the recipient, for whom it was intended, to change. The ultimate power therefore lies with the learner. Any system of feedback which locates control primarily with the person giving the feedback rather than the person for whom it is intended, is surely likely to be restricting its impact. Yet it is also recognised that teachers (in England) have the responsibility for the learning outcomes of their pupils. It is perhaps useful to note Gamlem and Smith's (2013) research on pupils' perspectives on feedback that 'trust' of the teacher is seen as paramount. It indicates a form of relationship where they accept power differences, yet have autonomy within the relationship. There must therefore be some sort of synthesis of power in the process of teaching and learning and a synergy of focus of what is to be learnt. Feedback could therefore be seen as an ideal mechanism through which power is shared in teaching and learning. Engeström (2000) promotes the notion of a zone in which there is some shaping of 'the distance or area between the individually experienced present and collectively generated foreseeable future' (2000: 157). There is a clear expectation that this is achieved 'with others'.

For Vygotsky the ZPD was characterised as a space in which the learner and a more knowledgeable other were in joint activity. However, learning is intrinsically social so that "through others, we become ourselves' (Vygotsky 1978:30). Vygotsky sets up the notion of the ZPD to show that it is with 'another' that current learning can be extended. This certainly raises the question about whether someone can learn alone. It also leads to the consideration of the mode of learning as well as the messages about outcomes. A relational approach to feedback will have congruence with a relational approach to pedagogy. Baines et. al. (2017) promote such an approach through their focus on group work, establishing the importance of pupils being co-constructors of their learning. When the curriculum is designed for collaboration, pupils can learn to contribute their ideas, raise questions, draw ideas together through collaboration and co-operation. As Watkins et al (2007: 90-91) suggest they become both 'help-givers' and 'help-seekers' as they reconcile multiple perspectives in the task of learning together. Implicit in such an approach is the use of language (which will be examined in the next section), and also the way in which pupils draw on their knowledge of the task, how they are achieving the goals, and their own learning experience to help regulate and direct the group effort. To some extent participants bring or respond to feedback, generated in the group, which is shaped around negotiating actions around the collective endeavour. Feedback can therefore become part of pupils' co-working in a less formal sense within a relational pedagogy. Such an approach also builds on Vygotsky's notion that all learning first happens on the interpsychological plane, that is between people (1978:57). However, when feedback is being considered, a point made by Newman et al (1989:57) about Vygotsky's thinking, seems particularly poignant. 'There is no assumption that all parties involved in the ZPD have the same notion of what was going on'. The precise messages often relayed in feedback may not be interpreted as intended (Hargreaves, 2013). Rather than dismissing such a position, as it breaks up uniform actions for whole classes and school, it needs to be understood and embedded into the way in which feedback might be nurtured with learners. It gives additional currency to the ways in which pupils may use feedback with each other, 
formally or informally. Furthermore, there are implications for the way pupils are helped to understand talk for different purposes in the classroom (Mercer et al, 2004).

More recent research (Dann, 2015 and 2018) showed how pupils who struggled to achieve in the way expected were lowering the cognitive challenge of the feedback they received or refused to acknowledge that there was anything in their work that they thought needed to be improved or were prepared to improve. This supports Kluger and DeNisi's findings (1996:260). Although there was recognition that the person giving the feedback (teacher) had a particular view, pupil thinking was not necessarily aligned to what was being asked. Pupils were not being subversive or trying to be difficult or non-compliant. Rather it was because the pupils struggled to internalise what was beyond their own thinking and priorities. The language of the feedback being given was not helpful to them, as they could not link it to their own learning realities. In such cases there are clearly differences in the way future learning is anticipated and prioritised between teachers and pupils. As Holland et al (1998) highlight it is important to understand these differences and what they mean for the participants as a starting point. This is certainly not easy when external accountability pressures require particular pupil attainments, demonstrated in particular ways.

Holland et.al's (1998) perspectives are of interest here and may offer further insights that develop from Vygotsky's work. Their notion of Figured World (FW) identifies a 'socially and culturally constructed realm of interpretation in which particular characters and actors are recognized, significance is assigned to certain acts, and particular outcomes are valued over others. Each is a simplified world populated by a set of agents ....who engage in a limited range of meaningful acts or changes of state.... as moved by a specific set of forces.' (1998:52). Holland et al's ideas shape a particular type of cultural context in which agents are socially related and positioned for the actions in which they are engaged. The school, and a classroom within it, can insightfully be seen in the context of figured world. As such it too could be identified as providing "the context of meaning and action in which social positions and social relationships are named and conducted" which is the essence of a figured world (1998: 60). As discussed by Holland et al, what is presented in their theorising moves on from Bourdieus's notion of 'field' which he describes as a separate social universe with its own laws of functioning (Bourdieu 1993:162). Figured world is more particularly located in the everyday aspects of cultural structures and relationships, seeing how these play out in ongoing daily activities. Thus, Holland et al's notion of figured world provides a broader context in which the notion of Vygotsky's ZPD might be extended. It helps to add some clearer dimensions to the space and relationships which Vygotsky presents. Figured worlds "take shape within and grant shape to the coproduction of activities, discourses, performances and artefacts" (51). Thus in identifying FW there is greater scope for identifying the varying interpretations of different actors in the process. It more directly identifies that a FW is "peopled by figures, characters, and types who carry out its tasks and who also have styles of interacting within, distinguishable perspectives on and orientations toward it." (51). This seems to capture the very different positions of pupils and teachers in the figured world of the school.

The lens of figured world theory can help us to examine the relationships in the classroom as part of the constructions and sharing of meanings. More particularly feedback can be seen in this figured world of the school in terms of a cultural tool. That is, a particular tool for communicating between pupil and teacher. It may also be seen as a cultural artefact, as the messages are not neutral or random, they are entrenched in particular histories and discourses (which may be quite different between teacher and pupil). Furthermore feedback can be seen as a mediating device having signs, symbols and codes, which are often most clearly seen in the way marking is conveyed to feedback to pupils. 
As this section has highlighted, understanding feedback must include the meanings and intentions of others. If both ZPD and the broader space of the figured world, are intended to have meanings, they are both intentional in their purpose. Yet culture, history, social interactions and activities may all lead to many different enactments within this world. When we consider the current priorities of education from each schools perspective, these are very clearly defined in terms of outcomes and standards. There is little scope for teachers to deviate without consequence. However, for the pupil, the consequences are not necessarily understood or even acknowledged. Consequences may be perceived differently by pupils according to their age, personal experiences, culture and context. What becomes of particular interests in the feedback relationship is the role, significance and use of language within feedback. Attention is turned to this so that it is explored from a starting point of Vygotsky's theory, but also drawing in Bakhtin $(1981,1986)$ and Holland et.al's synthesis of both.

\section{The significance of language in feedback}

The pedagogical relationship which is being shaped within the ZPD is premised by the use of language, which in Vygotsky's terms is a symbolic mediating device. Feedback, being primarily language based (whether written or spoken) is usually specifically focused and becomes a mediating devise. Particular meanings are assigned to its codes and to its structures which are designed to convey particular meanings and expectations to learners. Conversely, the way in which feedback is gathered by teachers from pupils as evidence for them to adjust their teaching may be less planned, and may be more ad-hoc and unequally received from cohorts of pupils. Feedback thus becomes a particular mediating device which helps to shape next steps of learning and phases of teaching. The way language features in this process is therefore pivotal.

But we must go further, focusing on a 'language' level concerns mainly the lexical. Where the sociocultural perspective takes a turn is to see language within its cultural, historical and institutional setting. Vygotsky's work points to this but does not develop this notion sufficiently. The work of Bakhtin offers a particular orientation which serves socio-cultural theory, and in the context of this paper, enables us to see why feedback is necessarily a relational concept. Language is often seen in a way in which words can be taken out of their context. For Bakhtin it is not the word that gives meaning but the whole utterance. 'Speech is always cast in the form of an utterance belonging to a particular subject, and outside this form it cannot exist' (1986:71). Thus words, whether spoken or written, are seen as speech. As such they are regarded as utterances with the distinctive features of 'voice' and dialogicality'. As 'voice', an utterance is always in a context with meanings therefore coming into existence when more than one voice exists. This notion builds on the preceding section related to others. Bakhtin therefore recognises both the voice of the speaker (or writer) and the voice of the listener (or recipient). Here the notion of addressivity is crucial. Each utterance is part of a chain of communication (1986:84). The utterances of the addressee are also a part of a communication chain, which are responses to other utterings. The addresser's utterances are also linked to previous voices. Thus, what is said or written are not isolated words, each utterance embraces the voices of others. They are intricately social and complexly contextual. Each utterance is concerned with both the author and the addressee. It has two voices, and in Bakhtin's terms, is inherently dialogic. 
In relation to feedback, the developments of Bakhtin's notion of words as part of speech and the conveying of meaning, intention, context, and history as part of a chain of communication, spans past and present directing the addressee to making sense of their learning for the future. Much of the research on feedback looks at technical components. It assumes that direct transmission of meaning can be both conveyed and received. Specific codes are used to represent mistakes or corrections. Rubrics may be used to frame gradings so that language is crafted to precisely distinguish levels of response. But if the words contained within feedback by the 'author' are understood in the way that Bakhtin suggests, they are far from the technical tool intended. Furthermore, it locates feedback as part of a dialogic exchange even if conveyed in written form only. It remains dialogic when identified as mediated action between the teacher and learner. Also, it steers slightly from Vygotsky's notion of 'inner speech' when learning becomes internalised (interpsychological plane). For Bakhtin, even inner speech retains the voices of others. Thus, it is seen as less of a technical reconceptualisation. It retains its social, and cultural meanings. Such understandings complement Alexander's work (2008 and 2018) on dialogic teaching. They show how the impact of dialogue persists into inner learnings and traverses social and cultural spaces in classrooms. Talk ' vitally mediates the cognitive and cultural spaces between adult and child, among children themselves, between teacher and learner, between society and the individual, between what the child knows and understands and what he or she has yet to know and understand' (2008:92). Building on this evidence it becomes clearer as to why feedback is often not acted upon, is partly acted on, or is interpreted in different ways from which the author intended. Perhaps the pretence, so prominent in our national education system that feedback is explicit, clear, objective, discreet, technical with pre-specified criteria, is a limited understanding.

Lotman (1988) suggests that the text (in this case feedback) has two functions, univocal (where the codes of the speaker and the listener coincide) and dialogic. This dual functionality is taken further by Bakhtin (1981: 294) who identifies that there are issues of power, privilege and position in the balance of this dual functioning for the individuals concerned (this is explored further in relation to identity). He recognises that 'the word does not exist in a neutral and impersonal language...but rather it exists in other people's mouths, in other people's contexts, serving other people's intentions: it is from there that one must take the word, and make it one's own.' Wertsch (1991) draws attention to this being a form of 'ventriloquation' (70). Taking this notion further there is certainly evidence in the literature of the way in which feedback is enacted and dominated by the language and criteria defining summative attainment measures. The teacher perhaps merely shaping feedback in the words of the criteria that shape national expectations upon which pupils must be judged as successful. Identifying feedback as a form of ventriloquism by the teacher, relaying the standards of the curriculum in the classroom, seems congruent with the policy narrative which pervades and has been seen in recent government White Papers in England $(2010,2016)$. The pressure to ensure pupils reach particular standards can sometimes overshadow the way in which they make sense of this narrative and can also mean that particular criteria are pushed in advance of the development of schema needed for them to engage in the required learning. Nevertheless the relational space, which has been framed by Vygotsky's ZPD and shaped by dialogue, reveals a distinction from some of the literature which presents a dialogic approach to teaching and learning (Wegerif, 2011). In this literature Vygotsky's 'cognitive structures', implicit in the ZPD, are not included. The focus is more on relationships and dialogue. This would not be adequate for framing feedback. The cognitive requirement remains important when feedback is the focus of language considerations. Extending the discussion of 'others' and of 'language', the importance of action is 
now considered as an additional, but related element of the notion of feedback as a relational concept.

\section{Feedback as action (within a process of self-authoring)}

Further drawing on socio-cultural theory, it is clear that the way learning is explored links to participants being active. They are co-producers of meaning. They have agency to make sense of themselves, others and the contexts they are in, both past and present. Even if their agency is reduced in physical terms in particular learning environments, from both Vygotsky and Bakhtin's perspectives they remain active in the process of shaping themselves. If feedback is to be a mediating tool which can be used as part of the activity of learning, it must be formed in a way in which each person can be in a state of being addressed as well as being in a state of answering, both are a state of action (Holland et al 1998:169). For Holland et al, Vygotsky and Bakhtin's work are brought together in the notion of figured world and the action of self-authoring. Indeed Holland et al suggest the ZPD could be viewed as a space for self-authoring (190). In Bakhtin's terms the meaning that we make of ourselves is found in the site of self-authoring. In Holland et al's terms it is "a space defined by the interrelationship of differentiated vocal perspectives on the social world" (p. 173). This takes the notion of the relational space in which feedback is being explored to being part of a broader space. It is not necessarily focused specifically on learning. The learner may be in multiple positions of activity in orchestrating the multiple voices from those $s /$ he addresses and is addressed by. So even in the classroom the 'voices of others', from previous experiences and other contexts may be included in the processes of self-authoring. The feedback which might be offered, which addresses the learner and to which the pupil must answer, does not sit in isolation. The way that the school may frame and shape it does not necessarily translate in the same way for all learners. Not only are issues of context, culture and history important in the way meaning is made as part of feedback but as we look through the lens of socio-cultural theory we see the learner as an active participant orchestrating both the messages which are shaped by school as well as those which are dominant in their life beyond school. The extent to which the voices and meanings distilled in school can co-exist with other discourses and voices will make a difference to the way in which an individual self-authors themselves within these narratives. As Bakhtin states "the process is made more complex by the fact that a variety of alien voices enter into the struggle for influence within an individual's consciousness" (1981: 348).

Within the literature on feedback it is clear that some learners are able to use feedback more effectively than others (Dann, 2018; Hargreaves, 2013). It may be that part of the way in which feedback is used relates to how the learner is able to make sense of the way feedback addresses $\mathrm{him} /$ her as part of the broader action of being in a figured world. Learners must develop their own 'authorial stance' (Holland et al: 183) in shaping and progressing learning. To some extent the way in which the pupil understands himself as a learner and locates this as part of his/her developing identity, thus becomes crucial. Feedback demands engagement and can therefore only be enacted through action.

\section{Feedback as a part of identity in practice}

Holland et al indicate that 'Identities become important outcomes of participation in communities of practice in ways analogous to our notion that identities are formed in the process of participating in 
activities organised by figured worlds' (1998:57). Thus as learners continue to participate in the school community and understand what is available to them as part of this figured world they have to work out how their developing self might change. Feedback can be seen as a key mediating tool in the figured world of the school which offers particular information designed for the learners to hear and to which they are 'expected' to respond. The three themes already discussed of 'other', 'language' and 'activity' are intricately bound together as part of the way in which feedback is heard and answered, shaping personal learning and teaching identities. The notion of identity is not straight forward as it traverses many theories. It requires some attention here as it is argued that learners (and teachers) are bound up in their own developing and shifting identities which are part of the person engaging with the details of the feedback process.

The importance of teasing out the concept of identity helps to frame how feedback is being understood in this paper. Holland at al (1998: 5) explain identity as 'a concept that figuratively combines the intimate or personal world with the collective space of cultural forms and social relations'. Identities are seen as 'the imaginings of self in worlds of action' (5). Unless learners can understand the trajectory of their learning as part of their own developing identity, learning may not proceed well. Black et al (2010) offer some useful insights in relation to mathematics development which are worth exploring and applying here. Underlying their thinking is Leontiev's work on psychological development of language (1981). In recognising that children engage in many activities, some activities can be identified as 'leading'. What is meant here is that the learner will become increasing aware that some activities will lead to new motivations and become more important than original motivations. These may refocus needs and help to shape future learning and development. However, there are many motives for actions in learning representing many subjectivities. Black et al (2010) present their notion of identity (or identities) as

'historical in origin and emerges from the subjectivities (how one views oneself) we experience in the process of doing activities. However, as we engage in many activities (and thus experience many subjectivities) through the course of our lives, we have a collection of identities to draw on at any one moment' (2010: 28)

Accordingly, they argue that the learner begins to develop hierarchies of identities born out of reflection-in-action and reflection-on-action. Identities which are chosen at any one moment will relate to what is perceived to be the dominant activity. Black et al refer to 'the identity made available by this leading activity as leading identity and suggest that this reflects a hierarchical organisation of motives in understanding the self' (2010: 58). The relationship here of language, activity, others and identity is interdependent. The relevance of such theorising is important for the way feedback is understood as relational. The message here is that feedback is socially and culturally situated and presumes that the curriculum is co-constructed with others. It also requires that the learner has sufficient motivation and cognitive schema to engage with the curriculum and the feedback, acknowledging that the learner must see the activity of engaging with the feedback and constructing meaning from it as sufficiently relevant to them. Thus, the engagement with feedback is not merely a matter of thinking about the content of learning, but of self in action with others. It requires both the use of a dimension of one's own hierarchically forming identity, and to some extent, if learning has taken place, opens up the possibility of other identities being challenged, relegated, or modified. Children of school age might be less clear about their developing identities, as they have fewer activities and experiences on which to draw. They may struggle with grasping the motivation that is required to drive their learning forward. But there is no notion of fixed and stable identity here. Perhaps like the statically framed notions of learning which dominate our education systems, identity can mistakenly be seen in simplistic and in fixed terms. If feedback can only be 
enacted as part of a process of self-in-action, the way in which identity may be of significance needs further exploration.

Both the teacher and learner have relative (or positional) identities (Holland et al: 127) in relation to one another, their actions, and their language. In the classroom context both teachers and pupils use feedback to focus their action, and their thinking for future behaviours will be in relation to how they see their own identity in relation to the others. Although this builds on the earlier section on 'others', here different relational (or positional) identities may or may not facilitate their choice of participation in particular communities. For learners to take advantage of the feedback available to them they may need to 're-mediate' their position in relation to both others and the cultural artefacts used to convey the messages available (137). The intention in the school system is that pupils learn the necessary dispositions to be learners and thus take on the positional/ relational identities of being a learner in the classroom, with feedback offering important messages to guide their behaviours and affirm power and priorities for what should be learnt. However, not all learners will find that their identities easily make sense in a school context and establishing one that sufficiently motivates them for learning to develop, may be problematic. 'The everyday context of lived identities..., may be relatively unremarked, unfigured, out of awareness, and so unavailable as a tool for affecting one's own behaviour (140) '.

Identifying feedback as a process which is as much about shaping identity(ies) in action as about specific curriculum messages is important. It adds an additional layer to the way in which this paper seeks to see feedback as a relational concept, which transcends knowledge and is part of each individual's position and understanding of themselves in context, and community.

\section{Conclusion and Insights for Practice}

Although this paper is primarily focused on presenting a specific theoretical underpinning for the process of feedback, and the interactional space in which it occurs in classrooms, there is some imperative to highlight the implications of such theorising for classroom practice. A substantial contribution to the significance for practice can be found in Dann (2018). Here the importance is to recognise that feedback is not merely a technical tool which is fixed in meaning and promotes predetermined outcomes. The way it is understood and enacted may vary from pupil to pupil. Teachers thus need to frame feedback carefully and be willing to talk with pupils about what it might mean and how it might be acted upon. This adds to Alexander's (2008 and 2018) work on the importance of talk and dialogue in the classroom. Alexander's (2018) work offers evidence for the importance of dialogue as part of pedagogy. This paper offers an argument for dialogue to be considered with greater seriousness as part of how assessment is used to improve learning through feedback. More research is required here to build on the contextual and theoretical issues outlined.

Some pupils may be quite independent in their use of feedback, having the motivation, alignment to school priorities, resourcefulness and cognitive skills to consider how it relates to their next steps. Other pupils may need support in understanding how it relates to them and possible subsequent actions. This may be simply addressed through further discussion, modelling of examples, or more focused questions which help to move thinking forward. Other pupils may struggle to position themselves alongside the feedback, so that they can answer the way in which it addresses them. This may result in pupils being disengaged. Without support to help them reimagine their future learning and themselves as learners, learning is unlikely to progress. 
As feedback is concerned with future learning, helping children to imagine themselves with new learning in the future is crucial. How we help children to see themselves differently, acquiring new learning, needs to be more carefully considered in schools. The implications from the theoretical considerations outlined in this paper point to the importance of the context of future learning being recognised as social, mediated and self-authored alongside the 'voices' of others. It may be that pupils can be a useful resource for narrating their most recent learning so that those who have yet to make these steps can see and listen to the learning story of their (slightly more advanced) peers. They can also see and relate to the people who embody this new learning and perhaps gain a greater sense of what it might do and who they might become in ways that are more immediate and more imaginable. Ways in which pupils might narrative and capture their learning journey over a year can be shared with the pupils in the year below are seldom researched. It may well be that more innovative and relational ways of helping pupils to understand themselves with new learning futures needs to become a more central tenant of ways of shaping feedback so that it can be more successfully enacted.

If the potential of feedback is to be fully realised, it needs to be powerful for all pupils. Not only should we draw on existing research evidence, but consider the pupils and the contexts where learning is more problematic. In offering feedback as a relational concept this papers opens up a range of new understandings which might prompt further thinking and action as the role of feedback continues to find its place in the purposeful interactions of teachers and pupils.

\section{References}

Alderson, J.C. and Wall, D. (1993) Does washback exist? Applied Linguistics 14: 115-129

Alexander, R. (2008) Towards dialogic thinking: rethinking classroom talk ( $4^{\text {th }}$ edition) York: Dialogos.

Alexander, R. (2018) Developing Dialogic teaching: genesis, process, trail. Research Papers in Education, 33(5), 561-598.

Au, W. (2011) Teaching under new Taylorism: high stakes testing and the standardisation of the $21^{\text {st }}$ century curriculum. Journal of Curriculum Studies, 43(1), 25-45

Ball, S. (1993) Education Policy, Power Relations and Teachers' Work British Journal of Educational Studies 41(2) 106-121

Bakhtin, M.M. (1981) The Dialogic Imagination: four essays by M.M. Bakhtin. Holoquist, M.E. ED. trans. Caryl Emerson and Michael Holoquist. Austin: University of Texas Press.

Bakhtin, M.M. (1986) Speech genres and other late essays, ed. And trans. Caryl Emerson. Minneapolis: University of Minnesota Press.

Baines, E., Blatchford, P., \& Kutnick, P. (2017) Promoting Effective Group Work in the primary Classroom, $2^{\text {nd }}$ edition. London: Routledge.

Baird, J., Andrich, D., Hopfenbeck, T. and Stobart, G. (2017) Assessment and Learning fields apart? Assessment in Education: Principles, Policy and Practice 24:3: 317-350 
Basford, J. and Bath, C. (2014) Playing the assessment game, Early Years: an international research journal 34(2) 119-132

Bennett, R.E. (2011) Formative assessment: a critical review. Assessment in Education: Principles, Policy and Practice, 19(1), 5-25

Black, L. William, J., Hernandez-Martinez, P., Davis, P., Pampaka, M. and Wake, G. (2010) Developing a 'leading identity': the relationship between students' mathematical identities and their career and higher education aspirations, Educational Studies in Mathematics 73: 55-72

Black, P., Harrison, C., Lee, C., Marshall, B., and Wiliam, D. (2004) Working inside the black box: Assessment for learning in the classroom. Phi Delta Kappan 86 (1), 8-21

Black, P. McCormick, R., James, M. and Pedder, D. (2006) Learning how to learn and assessment for learning: theoretical inquiry, Research Papers in Education, 2. 119-132

Black, P. (2015) Formative assessment - an optimistic but incomplete vision Assessment in Education: Principles, Policy and Practice 22(1) 161-177

Black, P. and Wiliam, D. 1998 Assessment and Classroom Learning, Assessment in Education, Principles, Policy and Practice, 5(1), 7-74

Black, P., and Wiliam, D. (2009) Developing the theory of formative Assessment, Educational Assessment Evaluation and Accountability, 21, 5-31

Black, P., and Wiliam, D., (2018) Classroom Assessment and Pedagogy, Assessment in Education: Principles, Policy and Practice DOI: 10.1080/0969594X.2018.1441807

Boud, D. and Molloy, E. (2013) Rethinking models of feedback for learning: the challenge of design, Assessment and Evaluation in Higher Education, 38(6), 698-712

Bourdieu, P. (1993) The Field of Cultural Production: Essays on Art and Literature. New York: Columbia University Press

Bradbury, A and Robert-Holmes, G. (2018) Datafication of Primary and Early Years Education: Playing with Numbers, London Routledge.

Broadfoot, P.M., Daugherty, R., Gardner, J, Harlen, W., James, M., and Stobart, G. (2002) Assessment for Learning: 10 Principles. Cambridge UK: University of Cambridge School of Education.

Carless, D. (2013) Trust and its role in facilitating dialogic feedback, Boud, D and Molly, L (eds.) Feedback in higher and professional education, Routledge: London pp 90-103

Chaiklin, S (2003) The Zone of Proximal Development in Vygotsky's analysis of learning and instruction. In Kozulin, A., Gindis,B., Ageyev, V. Miller, S. Vygotsky's educational theory in cultural context. Cambridge: Cambridge University press: 39-64.

Dann, R. (2015) Developing the foundations for dialogic feedback in order to better understand the 'learning gap' from a pupil's perspective, in London Review of Education 13(3), 5-20.

Dann, R. (2016) Developing understanding of pupil feedback using Habermas' notion of communicative action, Assessment in Education: Principles, Policy and Practice, 23(3): 396-414.

Dann, R. (2018) Developing feedback for pupil learning: Teaching, Learning and Assessment in Schools, London: Routledge. 
Department for Education (2010) The Importance of Teaching. White Paper: November 2010. London: HMSO

Department for Education (2015) Commission on Assessment without Levels: final report. London: HMSO

Department for Education (2016) Educational Excellence Everywhere. White Paper, March, London: HMSO

Educational Endowment Fund Education Endowment Foundation Teaching and Learning toolkit accessed online on $30^{\text {th }}$ January 2018

https://educationendowmentfoundation.org.uk/evidence/teaching-learning-toolkit

Engeström, Y. (2000) from individual action to collective activity and back: developmental work as an interventionist methodology, in Luff, P., Hindmarsh, J. Heath, C. (Eds) Workplace studies: recovering work practice and informing system design (Cambridge, Cambridge University press)

Gamlem, S.M. and Smith, K. (2013) Student perceptions of classroom feedback. Assessment in Education: principles, Policy and Practice 20(2) 150-169.

Gillen, J. (2000) Versions of Vygotsky. British Journal of Educational Studies 48:2, 183-198.

Hanson, F.A. 91994) Testing Testing: social consequences of the examined life. Berkeley: University of California Press.

Hargreaves, E. (2013) Inquiring into children's experiences of teacher feedback: Reconceptualising assessment for learning. Oxford Review of Education, 39:2, 229-246.

Harlen, W. (2005) Teachers' Summative Practices and Assessment for Learning - tensions and synergies 16(2): 207-223. Hattie, J. and Timperley, H. (2007) The Power of Feedback. Review of Education 17 (1) 81-112.

Hattie, J. (2009) Visible Learning London: Routledge.

Holland, D., Lachicotte Jr, W. Skinner, D. Cain, C. (1998) Identity and Agency in Cultural Worlds. Cambridge MA. Harvard University Press.

Johnson, S. (2013) On the reliability of high-stakes teacher assessment. Research Papers in Education 28(1): 91-105

Kingston, N. M., \& Nash, B. (2011). Formative assessment: A meta-analysis and a call for research. Educational Measurement: Issues and Practice, 30(4), 28-37.

Kingston, N. M., \& Nash, B. (2015). Erratum. Educational Measurement: Issues and Practice, 34(1), 55.

Kluger, A.N., and DeNisis, A. (1996) The effects of feedback interventions on performance: A historical review, a meta-analysis, and a preliminary feedback intervention theory. Psychological Bulletin, 119 (2), 254-284.

Latham, G.P. and Locke, E.A. (1991) Self-regulation through goal setting, Organisational Behaviour and Human Decision Processes, 50: 212-247 
Leontiev, A.A. (1981) Psychology and the Language Learning Process, Oxford: Pergamon.

Lingard, b. (2010) Policy Borrowing, policy learning: testing time in Australian Schooling. Critical Studies in Education 51(2), 129-145

Lotman, Y.M. (1988) Text within a text. Soviet psychology 26 (3):32-51

Madaus, G.G. (1988) The distortion of teaching and testing: High-stakes testing and instruction. Peabody Journal of Education, 65, 29-46

Mercer, N. and Fisher, E, (1992) How do teachers help children to learn? An analysis of teachers' interventions in computer-based activities. Learning and Instruction, 2, 339-355.

Mercer,N., Dawes, L. Wegerif, R. Sams, C. (2004) Reasoning as a scientist: Ways of helping children use language to learn science. British Educational Research Journal 30(3): 359-377

Nassaji, H. and Wells, G. (2000) What's the use of triadic dialogue?: An Investigation of TeacherStudent Interaction. Applied Linguistics, 21: 376-406

Newton, P.E. (2007) Clarifying the Purposes of Educational Assessment. Assessment in Education: Principles, Policy and Practice 14(2): 149-170

Newton, P.E. (2012) Clarifying the consensus definition of validity measurement, Interdisciplinary Research and Perspective 10(1-2),: 1-29

Popham, J. (1987) The Merits of Measurement Driven Instruction Phi Delta Kappa, May, pp 679-682

Pratt, N. (2016) Neoliberalism and the (internal) marketization of primary school assessment in England. British Educational Research Journal. 42(5) 890-905,

Pryor, J. and Crossouard, B. (2008) A sociocultural theorisation of formative assessment. Oxford Review of Education 34(1):1-20

Ramaprasad, A. (1983) On the definition of feedback, Behavioural Sciences 28, 4-13.

Scriven, M. (1967) The Methodology of Evaluation. In Perspectives of Curriculum Evaluation, eds. Tyler, R.W. Gagnes, R.M. and Scriven, M, 39-83. Chicago, 1L: Rand McNally.

Scrimsher, S. and Tudge, J.R.H (2003) The Reaching/Learning relationship in the first years of school: some revolutionary implications of Vygotsky's theory, Early Education and Development 14(3) 293312.

Shute, V. J. (2008) Focus on Formative feedback. Review of Educational Research, 78(1), 153-189

Sadler, D.R. (1989) Sadler, D.R. (1989) Formative assessment and the design of instructional systems. Instructional Science 18, 119-144.

Steen-Utheim, A and Wittek, A.L. (2017) Dialogic feedback and potentialities for student learning, Learning, Culture and Social Interaction 15, December, pp 18-30

Stobart, G. and Eggen, T. (2012) High stakes testing - value, fairness and consequences. Assessment in Education: Principles, Policy and Practice 19(1) 1-6

Stobart, G. (2008) Testing Times; The uses and abuses of assessment, London: Routledge 
Tanner, D. (2013) Race to the Top and leave the children behind. Journal of Curriculum Studies 45:1, 4-15

Torrance, H. and Pryor, J. (1998) Investigating Formative Assessment. Teaching, learning and assessment in the classroom. Buckingham: Open University Press.

Torrance, H. (2012) Formative Assessment at the Crossroads: conformative, deformative and transformative assessment. Oxford Review of Education 38: 3 pp.323-342

Tunstall, P. and Gipps, C. (1996) Teacher feedback to young children in formative assessment: a typology, British Educational Research Journal 22 (4) 389-404.

Vygotsky, L.S. (1978). Mind in Society: The development of higher psychological processes. (M.Cole, V. John Steiner, S Scribner \& E. Souberan Eds). Cambridge, MA: Harvard University Press. Originally written in 1930.

Watkins, C., Carnell, E., and Lodge, C. (2007) Effective Learning in Classrooms, London: Paul Chapman Publishing.

Wegerif, R. (2011) Towards dialogic theory of how children learn to think, Thinking Skills and Creativity. 6, pp 179-190

Wertsch, J.V . (1991) Voices of the Mind: A sociocultural approach to mediated action, Hertfordshire: Harvester Wheatsheaf.

Wiliam, D. (2011) Embedded Formative Assessment, Bloomington, IN: Solution Tree Press

Wiliam, D. (2016) Leadership for Teacher Learning, Florida: Learning Sciences International.

Wyatt-Smith, C., Klenowski, V., Gunn, S. (2010) The centrality of teachers' judgement practice in assessment: a study of standards in moderation. Assessment in Education, Principles, Policy and Practice 17(1): 59:75. 